\title{
Correction to: Psychometric properties of the SF-6Dv2 in an Iranian breast cancer population
}

\author{
Azin Nahvijou ${ }^{1} \cdot$ Hossein Safari ${ }^{2} \cdot$ Hosein Ameri $^{3}$
}

Published online: 26 March 2021

(c) The Japanese Breast Cancer Society 2021

\section{Correction to: Breast Cancer \\ https://doi.org/10.1007/s12282-021-01230-3}

The original version of this article unfortunately published with an incorrect funding number. The correct funding information should read as below. The Publisher regrets for the error.

Funding This study was funded by Tehran University of Medical Sciences and Health Services (26473).

Publisher's Note Springer Nature remains neutral with regard to jurisdictional claims in published maps and institutional affiliations.

The original article can be found online at https://doi.org/10.1007/ s12282-021-01230-3.

Hosein Ameri

hamery7@yahoo.com

1 Cancer Research Center, Cancer Institute, Tehran University of Medical Sciences, Tehran, Iran

2 Health Promotion Research Center, Iran University of Medical Sciences, Tehran, Iran

3 Health Policy and Management Research Center, Department of Health Services Management, School of Public Health, Shahid Sadoughi University of Medical Sciences, Yazd, Iran 